\title{
A cor dessa cidade sou eu: ativismo musicall no projeto Aya Bass 1
}

\section{The color of this city is me: musical activism in the Aya Bass project}

\section{Nadja Vladi Gumes}

Docente permanente do PPGCOM/UFRB, professora de comunicação do CECULT/UFRB e doutora em Comunicação e Cultura Contemporâneas/UFBA. E-mail:

nadjavladi@ufrb.edu.br (ORCID https://orcid.org/0000-0002-9989-554X)

\section{Marcelo Argôlo}

Mestrando do Programa de Pós-graduação em Comunicação da Universidade Federal do Recôncavo da Bahia, com apoio de bolsa da FAPESB.

E-mail: celo.argolo@gmail.com.

\section{RESUMO}

Este artigo se propõe uma análise sócio-comunicacional do projeto Aya Bass, formado pelas cantoras Larissa Luz, Luedji Luna e Xênia França, que fazem parte da cena contemporânea de música pop de Salvador. Como uma marca importante dessa cena, analisamos o ativismo e como ele se apresenta na performance das artistas no show realizado no Festival Sangue Novo e nas apresentações no Carnaval em Salvador. Também analisamos como o ativismo se apresenta em shows, álbuns, videoclipes, posicionamentos públicos, letras e sonoridades. A partir dessa análise, buscamos comprovar que está em curso o surgimento de uma cena de música pop ativista, que tem como características inicialmente percebidas o ativismo musical, a experiência político-

\footnotetext{
${ }^{1}$ Este artigo foi apresentado no GP Comunicação, Música e Entretenimento, XIX Encontro dos Grupos de Pesquisas em Comunicação, evento componente do $42^{\circ}$ Congresso Brasileiro de Ciências da Comunicação. A pesquisa tem o apoio do edital MCTIC/CNPq № 28/2018 - Universal/Faixa A.

Dossiê A Música e suas Determinações Materiais - $\underline{\text { https://revistaecopos.eco.ufrj.br/ }}$ 
estética e a articulação de elementos locais e globais nas músicas com fortes referências de territorialidades geográficas, afetivas e sonoras.

PALAVRAS-CHAVE: Cenas musicais; ativismo; territorialidades.

\section{RESUMEN}

Esto articulo se propone a un análisis socio-comunicacional del proyecto Aya Bass, de las cantantes Larissa Luz, Luedji Luna y Xênia França, que hacen parte de la escena contemporánea de música pop de Salvador. Como una marca importante de esa escena, analizamos al activismo y como él se presenta el en la actuación de las artistas en el concierto hecho en el Festival Sangue Novo y en las presentaciones en el Carnaval de Salvador. También analizamos cómo se presenta el activismo en conciertos, álbumes, videoclips, posiciones públicas, letras y sonoridad. De ese análisis, buscamos comprobar que está en curso el surgimiento de una escena de música pop activista, que tiene como características inicialmente percibidas el activismo musical, la experiencia políticoestética y la articulación de elementos locales y globales en las músicas con fuertes referencias de territorialidades geográficas, afectivas y sonoras.

PALABRAS CLAVE: Escenas musicales; activismo; territorialidades.

\section{ABSTRACT}

This article proposes a socio-communicational analysis of the Aya Bass project, formed by singers Larissa Luz, Luedji Luna and Xênia França, who are part of Salvador's contemporary pop music scene. An important mark of this scene, we analyze activism and how it presents itself in the performance of the artists in the show held at the Festival Sangue Novo and at Carnival performances in Salvador. We also analyze how activism presents itself in concerts, albums, video clips, public statements, lyrics, and sounds. From this analysis, we seek to prove that the emergence of an activist pop music scene is underway, whose initially perceived features are: musical activism, aestheticpolitical experience and the articulation of local and global elements in the music with strong references to geographical, affective and aural territorialities.

Keywords: Music scenes; activism; territorialities.

Às margens da Baía de Todos os Santos, Larissa Luz, Luedji Luna e Xênia França anunciam: "Eu agora vou cantar para todas as moças, eu agora vou bater para todas as moças, para todas as ayabás, para todas elas"2. Essa foi a abertura da apresentação de estreia do show Aya Bass, que aconteceu no Festival Sangue Novo no dia 26 de janeiro de 2019, no Porto de Salvador, local que foi uma das principais entradas de comércio do

\footnotetext{
2 Trecho da canção "As Ayabás", de Caetano Veloso e Gilberto Gil, interpretada pelas cantoras Larissa Luz, Luedji Luna e Xênia França no show do projeto Aya Bass no Festival Sangue Novo em 26 de janeiro de 2019.
}

Dossiê A Música e suas Determinações Materiais - https://revistaecopos.eco.ufri.br/

ISSN 2175-8689 - v. 23, n. 1, 2020

DOI: 10.29146/eco-pos.v23i1.27454 
Atlântico Sul até o século XIX e hoje é parte do roteiro turístico da cidade. 0 projeto Aya Bass também foi para as ruas durante o Carnaval com três apresentações: a primeira na

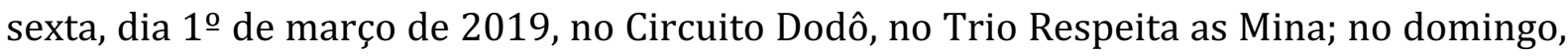
dia 03 de março de 2019, no palco montado na Praça Castro Alves, por onde passam os trios elétricos do Circuito Osmar; e no palco montado no Largo do Pelourinho3.

O nome escolhido pelas artistas para batizar o projeto é uma referência ao termo em iorubá ${ }^{4}$ yabás, que significa mãe-rainha e se refere às orixás femininas (Nanã, Iemanjá, Iansã, Oxum, Obá e Euá) cultuadas no candomblé. Ao mesmo tempo, faz alusão à cultura do grave da música eletrônica, uma das referências estéticas do projeto e da cena musical contemporânea de música pop em Salvador, da qual as três cantoras estão entre as principais representantes. A cena está ancorada em Salvador, ou, pelo menos, em um imaginário territorial da capital da Bahia, o que nos leva também a pensar o fenômeno na dimensão funcional e simbólica das territorialidades. Nessa perspectiva, o artigo analisa o projeto Aya Bass no Festival Sangue Novo, mas também observa suas apresentações no Carnaval, um evento que é parte importante nesta reflexão porque é o principal fio condutor para uma série de experiências com diversos atores em cena: bandas, charangas, trios elétricos, palcos, afoxés, baterias, batucadas, samples, caixas de som, tambores, guitarra baiana (Gumes, 2018), que disputam afetos e territorialidades.

Participar do Carnaval é condição necessária para fazer parte do circuito afetivo e econômico da capital baiana, pois o evento é parte da complexidade da cidade, é o espaço em que diversas práticas culturais interagem. Dessa forma, acreditamos que a presença da Aya Bass, com várias apresentações nos dias do Carnaval, é uma experiência significante para disputar um espaço fundamental na cena da música pop baiana e compartilhar afetos. Afeto, como coloca Grossberg, é uma característica fundamental na música popular por sua capacidade de nos levar para espaços sociais, físicos e

\footnotetext{
${ }^{3}$ Circuito aqui é utilizado como uma nomenclatura que o poder público municipal de Salvador batiza as territorialidades nas quais divide o fluxo dos eventos carnavalescos, e não como uma noção teórica. Citamos o Circuito Dodô, que compreende a Avenida Oceânica entre o Farol da Barra e o monumento As Meninas do Brasil, no cruzamento com a Avenida Adhemar de Barros, e o Circuito Osmar, que começa na Praça Dois de Julho, no Campo Grande, segue pela Avenida Sete de Setembro até a Praça Castro Alves e termina na Rua Carlos Gomes.

${ }^{4}$ Língua nigero-congolesa do grupo Kwa, falada por esse povo, e que chegou ao Brasil com xs africanxs escravizadxs.
}

Dossiê A Música e suas Determinações Materiais - https://revistaecopos.eco.ufri.br/

ISSN 2175-8689-v. 23, n. 1, 2020

DOI: 10.29146/eco-pos.v23i1.27454 
emocionais afetivos. "O afeto atua por meio de nossos sentidos e experiências, de todos os domínios de influências que constituem a vida cotidiana" (Grossberg apud Shuker, 1999, p. 16). Janotti Jr argumenta que “os afetos são lugares privilegiados de percepção local" (2003, p.2). Ao investirmos em determinadas afetividades (gênero, etnia, musicalidades), estamos "preenchendo as cidades com práticas afetivas" (ibidem), e é nessa perspectiva que trazemos a ideia de afeto como uma ferramenta que nos auxilia a refletir sobre as formações e contornos de uma cena de música pop ativista em Salvador e como ela aciona determinadas práticas culturais afetivas.

Essa pesquisa já mapeava, separadamente, as artistas Larissa Luz, Luedji Luna e Xênia França como parte da nova cena de música pop ativista de Salvador. Em 2018, observamos que as três artistas resolveram se reunir para algumas apresentações durante o verão de 2019 em Salvador, especificamente no Festival Sangue Novo e no Carnaval, com o projeto nomeado Aya Bass, uma homenagem às cantoras negras da Axé Music. Em 2020, Aya Bass voltou a se apresentar, uma única vez, no carnaval, reivindicando o protagonismo negro na festa, o que nos fez perceber como o fenômeno apontava importantes pistas para pensar a nova música pop baiana a partir de memórias, afetos, recortes raciais e de gênero.

A partir de observação participante, da escuta das canções, da realização de entrevistas, da análise de reportagens de jornais e sites de notícias, e de performance midiatizada 5 , a nossa tentativa neste artigo é uma análise sócio-comunicacional para entender o que denominamos aqui de ativismo musical das Aya Bass, presente a partir do tensionamento de questões étnico-raciais e de gênero, como um elemento de articulação com a cena musical na qual o projeto está inserido. Dessa forma, este artigo tem por objetivo apresentar elementos dessa cena (Straw, 1991, 2006) com foco no ativismo musical (Herschmann, Fernandes, 2014) do projeto Aya Bass e na trajetória das cantoras baianas Larissa Luz, Luedji Luna e Xênia França, para entender como essas artistas questionam exclusões étnico-raciais e desigualdade de gênero em uma

\footnotetext{
${ }^{5}$ Agradecemos à equipe da produtora Movida Conteúdo, na pessoa de Dayse Porto, por ceder as imagens na íntegra do show Aya Bass no Festival Sangue Novo para nossa análise.

Dossiê A Música e suas Determinações Materiais - https://revistaecopos.eco.ufri.br/ ISSN 2175-8689-v. 23, n. 1, 2020

DOI: 10.29146/eco-pos.v23i1.27454
} 
performance intermediada pela música. Como essas experiências afetam a cidade e o debate que suscitam sobre gênero, etnias e sonoridades.

\section{Que cena é essa?}

Uma das noções que lançamos mão neste artigo é sobre o conceito de cena para entender melhor a cidade como principal articuladora das práticas culturais. Pensamos as cenas como uma rede que engloba e articula uma grande complexidade de agentes do cotidiano da urbe. Artistas, fãs, produtores, jornalistas, donos de casas de shows, entre muitxs outrxs, estão envolvidxs nas dinâmicas das cenas musicais. Essa noção, cunhada inicialmente por Will Straw $(1991,2006)$, busca "dar conta de uma série de práticas sociais, econômicas, tecnológicas e estéticas ligadas aos modos como a música se faz presente nos espaços urbanos" (Janotti Jr. e Pires, 2011, p. 11). Na primeira definição do início dos anos 1990, Straw buscou dar ênfase aos processos identitários que os agrupamentos das cenas musicais formavam. A cena seria uma espécie de contexto, "no qual práticas musicais coexistem, interagindo umas com as outras, dentro de uma variedade de processos de diferenciação e afiliações, de acordo com trajetórias variantes de mudança e fertilização mútua" (Herschmann, 2013, p. 44).

Neste artigo, nos interessa pensar a partir da segunda perspectiva que Straw trouxe para a noção de cenas musicais em 2006, quando passa a enfatizar os aspectos espaciais e uma variedade de pontos, inclusive afetivos, na análise das cenas (Straw, 2006; Herschmann, 2013). Na leitura de Simone Pereira de Sá (2011) sobre as ideias de Straw, a cena é o movimento das pessoas entre um lugar e outro, o que cria uma rede que permite sociabilidade e se conecta com a cidade. Com esse olhar, nossa proposta de análise do projeto Aya Bass é articular as afetividades que as três cantoras convocam e expandir essa articulação para pensar a rede na qual estão inseridas (dentro do arcabouço mais amplo da pesquisa) e, a partir disso, defender a formação de uma cena de música pop ativista em Salvador, fomentada a partir de 2009 com o surgimento do BaianaSystem.

Dossiê A Música e suas Determinações Materiais - https://revistaecopos.eco.ufri.br/ ISSN 2175-8689-v. 23, n. 1, 2020

DOI: 10.29146/eco-pos.v23i1.27454 
Cabe pontuar que as reflexões trazidas neste artigo são um recorte do projeto de pesquisa A música pop é global, mas o sotaque é local - territorialidades, cosmopolitismos, valorações e a construção de cenas da música pop do Sul Global ${ }^{6}$, que se concentra nos cenários urbanos por percebê-los como espaços privilegiados para a compreensão dos fenômenos culturais. Para Herschmann há uma valorização da espacialidade nas práticas musicais, o que nos permite entender que a noção de territorialidade/multiterritorialidade possibilita uma melhor análise da forma como a sonoridade da Aya Bass ocupa espaços e legitima determinados agrupamentos sociais. Herschmann pontua que:

(...) a noção de territorialidade ou até multiterritorialidade (Haesbart, 2002, 2010 e 2012) parecem ser mais adequadas para analisar as dinâmicas que envolvem de modo geral os agrupamentos sociais - a maior parte deles "juvenis" (MartínBarbero, 2008; Canclini e outros, 2012; Borelli e outros, 2009; Margulis e outros, 1998) - em um mundo contemporâneo marcado por nomadismos e fluxos intensos (Maffesoli, 2001). (2013, p. 49)

Para entender a experiência de cidade que um projeto sonoro formado por mulheres negras ativistas proporciona, a perspectiva trazida pelo geógrafo Haesbaert (2005) possibilita compreender como a noção de territorialidades permite um entendimento mais abrangente do fenômeno pensado a partir de um espaço socialmente construído. Haesbaert chama atenção para o fato de que a territorialidade incorpora dimensões políticas, econômicas e culturais porque mostra como "as pessoas se organizam no espaço e como elas dão significado ao lugar". (Haesbaert, 2005, p. 6776).

Sabemos a importância que as cidades têm tido nos estudos da cultura; por isso, ao pensarmos como essas práticas musicais ressignificam o espaço urbano, compactuamos com a ideia de Straw que atualiza e vincula o conceito de cena com os estudos culturais urbanos: "Cena, agora, retorna para nós como a questão da visibilidade na vida urbana" (Straw, 2017. p. 79). E como coloca Herschmann (2013), a noção de cena nos ajuda a "analisar a dinâmica da música e dos atores envolvidos no espaço" (2013, p. 48). Dessa forma, Salvador e suas multiterritorialidades (sonoras, étnicas-raciais, sociais, políticas)

\footnotetext{
${ }^{6}$ Essa pesquisa tem o apoio do edital MCTIC/CNPq № 28/2018 - Universal/Faixa A.

Dossiê A Música e suas Determinações Materiais - https://revistaecopos.eco.ufri.br/ 
se tornam protagonistas dessa pesquisa para entender a nova cena de música pop ativista e como o projeto Aya Bass circula o seu som e contribui socialmente, politicamente e esteticamente na construção dessa cena de música pop ativista em uma cidade formada majoritariamente por uma população negra7 .

\section{Música pop ativista}

O trabalho aqui analisado busca uma perspectiva do que Herschmann e Fernandes (2014) chamam de "ativismo musical", que seria uma inovação relevante do mundo da música, em que esses atores desenvolvem estratégias para "ressignificação das territorialidades e do cotidiano urbano" (Herschmann; Fernandes, p.25, 2014), sem uma clara hierarquia, mas respondendo a uma demanda comum (ibidem). 0 projeto Aya Bass constrói uma experiência política/estética que coloca no mesmo patamar o trabalho musical e o discurso ativista em prol do feminismo negro. 0 show apresentado pelas cantoras no Festival Sangue Novo, em Salvador, traz na sonoridade elementos locais (pagode, ijexá, samba-reggae e samba afro, todos oriundos de matrizes afrodescendentes) combinados a outros transnacionais (sons graves, $d u b$, música eletrônica, rap, reggae, afrobeat), costurados com um discurso político em uma linguagem pop. Esse novo idioma estético (Regev, 2013), que inspira artistas da música pop ativista de Salvador, representa uma espécie de resistência simbólica ao lugar periférico a que essas práticas estariam submetidas no campo de produção cultural, negociando, dessa forma, seu espaço, observando nesse fenômeno o que Bhabha chama do direito de expressão da "periferia do poder" (Bhabha, 1998).

Partindo dessa perspectiva, a ideia do Aya Bass é levar para o palco a voz de mulheres negras que, ao longo da história da música baiana, principalmente do Axé Music $^{8}$, foram colocadas em um papel secundário. Durante o show no festival, elas citam nomes de cantoras como Marcia Short e Alobêned, que ganharam destaque como

\footnotetext{
7 Dados do Instituto Brasileiro de Geografia e Estatística (IBGE) mostram que 82,7\% da população de Salvador se autodeclara negra, sendo $36,5 \%$ pretxs e $45,6 \%$ pardxs.

8 "A Axé Music é o encontro da música de blocos de trio elétrico com a música de blocos afro (frevo baiano + samba-reggae). É um estilo mestiço cuja linguagem mistura sonoridades harmônicas e percussivas" (GUERREIRO, 2001, p. 133).
}

Dossiê A Música e suas Determinações Materiais - $\underline{\text { https://revistaecopos.eco.ufrj.br/ }}$ 
cantoras da Banda $\mathrm{Mel}^{9}$ nos anos de 1980; Margareth Menezes, uma das primeiras a dar voz ao hit do Carnaval de Salvador de 1987, "Faraó - Divindade do Egito"10; Virgínia Rodrigues, reconhecida pela voz grave e pelo estilo que mescla música clássica, samba e jazz; e Patrícia Gomes, cantora da primeira formação da banda Timbalada ${ }^{11}$. Ao repensar o lugar dessas cantoras negras no Axé Music nos anos 1980 e 1990, acreditamos que há por parte dessas artistas contemporâneas uma resistência a uma estratégia (De Certeau, 2014) forjada por um lugar de poder. Dessa forma lançam mão, em um jogo de sobrevivência, de maneiras de habitar e utilizar o lugar (ibidem) usando a ferramenta do feminismo negro como uma forma de movimentar-se em um campo controlado pelo inimigo. Nessa perspectiva, nosso esforço é entender como a música operacionaliza essas tensões e conflitos e problematizar como artistas da cena estudada utilizam determinados afetos para a construção de um discurso social mediado pela sonoridade que dá visibilidade aos corpos negros rebatendo uma estratégia (ibidem) da ordem dominante em que a mulher negra é vista como o outro do outro (Kilomba, 2008).

O que acontece em Salvador na segunda década do século XXI é parte de um movimento que o pesquisador israelense Motti Regev (2013) chama de "cosmopolitismo estético", no qual artistas legitimam suas singularidades locais em um diálogo com um campo global de certas tendências estilísticas, incorporam novos "idiomas estéticos" (Regev, 2013) e entram no "circuito de globalização cultural" (ibidem), que observamos aqui como um espaço de criação de novas culturas que se relacionam em redes e fluxos de enorme interação, que gostaríamos de chamar de transculturalismo, um conceito que, como coloca Benessaieh, "captura mudanças culturais altamente diversificadas em uma sociedade contemporânea que se tornou globalizada" (2010, p.11).

Dessa forma, a performance corrobora a articulação de elementos transculturais com o discurso político. A concepção é inspirada nas raízes ancestrais convocadas pelas artistas e cada uma traz o arquétipo de uma yabá: Iansã, Oxum e Iemanjá. A banda que acompanha as cantoras é formada majoritariamente por mulheres cisgênero, e todas negras: Deise Fatuma e Nanny Santos, na percussão; Suyá Nascimento, na guitarra. Além

\footnotetext{
${ }^{9}$ A banda surge em 1984 e foi uma das principais precursoras da Axé Music.

${ }^{10}$ Considerado o primeiro samba-reggae da história, foi lançando no Carnaval de 1987.

${ }^{11}$ Banda lançada em 1991 por Carlinhos Brown que tem como principal instrumento o timbal.

Dossiê A Música e suas Determinações Materiais - https://revistaecopos.eco.ufri.br/ ISSN 2175-8689 - v. 23, n. 1, 2020

DOI: 10.29146/eco-pos.v23i1.27454
} 
delas, completam a banda o homem trans Ziat Franco, no baixo; e Ênio, único homem cisgênero, nas programações eletrônicas. Há aqui uma reivindicação de "lugar de fala" (Ribeiro, 2017) trazendo para o debate o que podemos chamar de feminismo negro, ou um "feminismo afrolatinoamericano", como defende Lélia Gonzales (1988), em que a exclusão se dá por uma questão racial, além do gênero, de forma que as mulheres latinas indígenas e negras são mais vulneráveis ao poder hegemônico do que as mulheres latinas brancas.

Tendo o ativismo como linha mestra da sua experiência musical, o projeto Aya Bass apresenta um repertório que mescla canções das carreiras individuais com músicas interpretadas originalmente pelas cantoras citadas acima e, ainda, um cover do grupo Destiny's Child, que foi formado pelas cantoras negras Beyoncé, Kelly Rowland e Michelle Williams. Durante a performance das baianas no Festival Sangue Novo para a canção "Survivor", originalmente gravada pelo trio estado-unidense, o telão do palco, que exibia animações, vídeos e outras imagens, apresentou uma animação na qual se lia Nordestiny's Child, um trocadilho que marca ao mesmo tempo uma reivindicação essencialista de identidade (Woodward, 2000) ligada à territorialidade da região Nordeste e a aspectos transnacionais, pela apropriação da língua inglesa.

O ativismo musical não é algo recente para as mulheres negras. Angela Davis já chamou a atenção para a capacidade da música de mobilizar e influenciar conhecimentos para as pessoas negras "criando uma comunidade estética de resistência" (Davis apud Collins, 2019, p. 282). A socióloga norte-americana Patricia Hill Collins (2019) observa o protagonismo que o blues teve para as mulheres trabalhadoras afro-americanas no entendimento do tecido social em que estavam inseridas com canções importantes sobre passado, tradições e política, que ajudavam a elucidar a situação de racismo e sexismo. Collins observa que músicas de Ma Rainey12 "validaram as tradições intelectuais feministas negras expressadas por mulheres negras da classe trabalhadora" (2019, p. 284).

\footnotetext{
12 Considerada a "mãe do Blues", é uma das mais antigas cantoras do gênero e uma das primeiras da sua
} geração a gravar uma música.

Dossiê A Música e suas Determinações Materiais - https://revistaecopos.eco.ufri.br/ 
Voltamos à apresentação no Festival para entender o ativismo musical como uma das marcas dessa cena. 0 momento de maior teor político foi a fala de Larissa Luz, na qual ela tensiona a questão da representação da população negra em espaços de poder:

\begin{abstract}
Essas são as verdadeiras donas da música preta da Bahia. Querem a música dos pretos, mas não querem os pretos; querem a dança dos pretos, mas não querem os pretos; querem os cabelos dos pretos, mas não querem os pretos. Então, aqui vai um recado para a branquitude: está na hora de fazer concessão; está na hora de parar de usar de um discurso que não é seu para lucrar; está na hora de parar de usar de um lugar de fala que não é seu para ganhar. Porque preto de alma não existe! O Brasil é um país que mata, é um país que humilha, é um país que condena a cor da pele e não a cor da alma! Quem é preto é preto, quem não é, não é! E a música preta é nossa!" (informação verbal) ${ }^{13}$.
\end{abstract}

Ao mandar um recado claro e direto para a cantora Daniela Mercury, batizada de rainha do axé, que gravou sucessos de blocos afros e que havia lançado, próximo à data do show das Aya Bass no Festival Sangue Novo, a música “Pantera Negra Deusa” (2019), que fala de Wakanda e África, Larissa Luz reivindica um lugar de protagonismo negro na música baiana. Também descortina o presente - mas "velado" - racismo baiano que relegou ao segundo plano cantoras negras como Margareth Menezes e Marcia Short, importantes na construção da Axé Music, e elegeu como estrelas Daniela Mercury, Ivete Sangalo e Claudia Leitte, todas brancas. A pesquisadora Liv Sovik (2009), quando pensa o fenômeno da branquitude, traz uma análise sobre a relação tensa e conflituosa de Daniela Mercury como a "porta-voz da cultura musical negra de Salvador", apontando como essa "encenação", esse "mascaramento", acentua fissuras nas conflituosas relações étnico-raciais, materializadas na fala de Larissa Luz.

No livro Corpos em Aliança e a política das ruas - notas para uma teoria performativa de assembleia, a filósofa Judith Butler (2018) traz uma provocante abordagem sobre corpos, espaço público e manifestações populares com reflexões pertinentes sobre a dimensão expressiva dos corpos, o que leva a um dos pontos centrais da sua obra: pensar como esses corpos podem desenvolver ações coletivas para sair da condição precária e serem visíveis. A busca pelo direito de aparecer como

${ }^{13}$ Fala da cantora Larissa Luz durante o show do projeto Aya Bass no Festival Sangue Novo no dia 26 de janeiro de 2019.

Dossiê A Música e suas Determinações Materiais - https://revistaecopos.eco.ufri.br/

ISSN 2175-8689 - v. 23, n. 1, 2020

DOI: 10.29146/eco-pos.v23i1.27454 
mulheres negras e artistas é parte importante do discurso dessas artistas, desse ativismo musical, e, como coloca Butler, as possibilidades de visibilidade são elementos importantes para a corporificação, ação que elas fazem quando acionam esse lugar de fala na performance no Festival Sangue Novo, um espaço midiático de muita visibilidade na cidade, como veremos a seguir.

\section{Territorialidades conquistadas}

Projeto paralelo das três artistas, a estreia no verão baiano em um Festival com extensa cobertura dos meios de comunicação deu muita visibilidade para Aya Bass e seu ativismo. 0 Festival Sangue Novo é oriundo do programa de rádio de mesmo nome, que foi ao ar por cerca de sete anos (e saiu da programação em outubro de 2019) na GFM, uma das rádios da Rede Bahia, o maior grupo do estado de mídia, conteúdo e entretenimento, como a própria empresa se define no site oficial ${ }^{14}$. 0 idealizador e curador do festival é o jornalista Hagamenon Brito, que também foi o apresentador do programa durante todo o período em que esteve no ar. Na época da edição do Festival Sangue Novo, em 2019, Brito também atuava como editor e colunista de música do Jornal Correio, também da Rede Bahia, líder de vendas em Salvador. 0 show do Aya Bass fez parte da programação da terceira edição do festival, que contou com shows da cantora Duda Beat e do cantor Otto, ambos pernambucanos, e dos baianos Bayo, Hiran e Baco Exu do Blues, que também performam na atual cena de música pop de Salvador.

O festival é uma territorialidade privilegiada dentro das cenas musicais, por sua ligação com atores sociais com grande capacidade de mobilização dentro da rede, como o idealizador e a empresa, que garantem uma ampla cobertura midiática em seus canais: rádios, jornal, sites, redes sociais e a TV Bahia, canal afiliado à TV Globo. Além disso, o festival se torna, também pela capacidade de mobilização de agentes envolvidos na realização, uma das principais pautas em toda a imprensa da cidade. Dessa forma, a presença de Larissa Luz, Luedji Luna e Xênia França, artistas que convocam uma construção de raça e identidade de gênero, de mulheres negras baianas que "vivem

\footnotetext{
${ }^{14}$ Site oficial da Rede Bahia: http://redebahia.com.br/a-rede-bahia. Acesso: 06 jun. 2019.
}

Dossiê A Música e suas Determinações Materiais - https://revistaecopos.eco.ufri.br/ 
dignamente da sua arte" (informação verbal) ${ }^{15}$, aliada ao discurso em defesa da população negra, é, em geral, de grande potência na cidade de Salvador. As três artistas usam essa territorialidade como um lugar de movimento de resistência para determinados grupos sociais oprimidos (mulheres e negrxs), e a música é a ferramenta que utilizam para operar esse confronto.

A partir do acompanhamento das trajetórias individuais de cada uma das cantoras do projeto aqui analisado, podemos perceber como esses elementos que compõem a experiência compartilhada no show também estão presentes nos trabalhos solos. Larissa Luz, logo no início da carreira, assumiu o vocal da banda Ara Ketu ${ }^{16}$, uma das mais tradicionais da Axé Music e do Carnaval de Salvador. A cantora permaneceu no grupo entre 2007 e 2012, quando saiu em carreira solo. A partir do segundo álbum da nova fase, Território Conquistado, de 2016, passou a apresentar um trabalho que articula elementos locais (como a música dos blocos afros) e transnacionais (como os sons graves da música eletrônica) aliados a um discurso político que traz à tona questões relacionadas ao racismo e ao machismo. Canções como "Bonecas Pretas", na qual ela questiona a ausência de representatividade negra nos brinquedos infantis ("procuramse bonecas pretas", diz o refrão da canção), e "Meu Sexo", que reivindica a liberdade sexual feminina ("é o meu sexo, quem disse que é pra você?", questiona o refrão) são exemplos de como esse discurso aparece. Em 2019, lançou o álbum Trovão, em que reforça o caráter ativista articulado a uma estética que se relaciona com o afrofuturismo, movimento que propõe trazer referências da ancestralidade africana, mas de uma forma não tradicionalista, vista com uma roupagem inovadora, inexplorada ou futurista. 0 álbum Trovão, de certa forma, dialoga com as cantoras afro-americanas de blues, porque, quando traz a ancestralidade da religiosidade de matriz africana em negociação com bases eletrônicas e as letras politizadas, contribui para um debate político/estético e abre espaço para a expressão das mulheres negras sobre a sua história.

Luedji Luna, por sua vez, apresenta um trabalho que explora sonoridades acústicas. Em seu primeiro, e, por enquanto, único álbum, intitulado Um Corpo no Mundo

\footnotetext{
15 Fala de Luedji Luna durante o show Aya Bass no Festival Sangue Novo no dia 26 de janeiro de 2019.

16 Bloco formado em 1980 por moradores de Periperi, subúrbio ferroviário de Salvador.
}

Dossiê A Música e suas Determinações Materiais - https://revistaecopos.eco.ufri.br/ 
(2017), constrói uma música baseada principalmente na tradição da canção brasileira, no jazz, ritmos do congo, samba, reggae e claves rítmicas muito presentes na música baiana. A essas características se unem letras que abordam temas como pertencimento, imigração e a identidade afro-brasileira. Os músicos que formam a banda com a qual ela grava o disco mostram o transculturalismo presente no trabalho: o queniano Kato Change, na guitarra; o paulista criado na Bahia e filho de congoleses François Muleka, no violão; o cubano Aniel Somellian, no baixo; o soteropolitano Rudson Daniel, na bateria; e o sueco radicado na Bahia Sebastian Notini, na percussão e na produção musical. Em apresentações ao vivo, ela se posiciona politicamente em relação às questões étnicoraciais e de gênero. Por exemplo, em um show no dia 17 de agosto de 2018 no Teatro Castro Alves ${ }^{17}$ (TCA), uma territorialidade central para as artes da Bahia, por ser o principal equipamento cultural do Estado, ela afirmou: "parem de nos matar", em referência à violência policial que acomete a população negra, e de gênero, que vitima as mulheres.

Já Xênia França surgiu como cantora na banda Aláfia ${ }^{18}$ e, em 2017, lançou o primeiro álbum solo, intitulado Xênia. Tanto como parte do grupo, quanto no trabalho individual, a artista pautou a sonoridade em estéticas de matrizes africanas, em que dialoga com hip hop, jazz e a cultura iorubá. 0 disco homônimo aborda nas canções temas como diáspora negra, religiosidade e racismo. No trabalho, regravou, por exemplo, a música "Respeitem Meus Cabelos, Brancos", composta e interpretada originalmente pelo cantor paraibano Chico César. Em entrevista ao site Vice, Xênia fala da importância do seu ativismo quando coloca que “(...) a voz para a pessoa negra é uma ferramenta muito poderosa. E Xênia [o disco] é um ensaio sobre ter voz" (Moura, 2017). A canção "Pra que me chamas?" traz palavras em iorubá, uma percussão cubana e uma letra potente para falar de racismo e a polêmica questão das "apropriações culturais". Ou seja, ao problematizar as questões étnico-raciais e de gênero, mostra como a música tem

\footnotetext{
17 Maior e mais importante teatro de Salvador. Oficialmente inaugurado em 1967, é o principal palco em Salvador para artistas nacionais e internacionais consagradxs. Ao se apresentar no TCA, Luedji Luna legitima seu espaço na música brasileira pela representatividade dessa territorialidade na história das artes da cidade.

${ }^{18}$ Big Band paulistana que mistura toques de candomblé com soul e rap.
}

Dossiê A Música e suas Determinações Materiais - https://revistaecopos.eco.ufri.br/

ISSN 2175-8689-v. 23, n. 1, 2020

DOI: 10.29146/eco-pos.v23i1.27454 
a função social de dar voz às mulheres negras, uma das características que vem marcando a cena de música pop ativista de Salvador.

Se nos anos 1970 Salvador passou por um processo de "reafricanização" (Risério, 1981) com o surgimento do Ilê Aiyêe ${ }^{19}$ (1974) e posteriormente do Olodum ${ }^{20}$ (1979) e do samba-reggae, na segunda metade do século XXI xs artistas negrxs da cidade se projetam em uma releitura dessa "reafricanização" e um flerte com o movimento afrofuturista, termo criado pelo teórico Mark Dery a partir de artistas que trabalham com questões afro-americanas usando a tecnologia e a ficção. Essa "blackitude" (Risério, 1981) permeia o trabalho do Aya Bass; entretanto, o diálogo contemporâneo com questões sobre feminismo negro, gênero, o uso do grave e bases eletrônicas trazem novas interpretações do que é ser negrx em Salvador, principalmente a mulher negra, que busca protagonismos na cena da música pop baiana, e luta pelo direito de aparecer, de visibilidade dos seus corpos no espaço público (Butler, 2018) e no debate político.

Larissa, Luedji e Xênia cantam sobre mulheres negras, racismo, sexismo, preconceito religioso. Todas essas questões estão nas letras das canções, na harmonia, no ritmo, nas parcerias com compositoras, cantoras e músicxs negrxs. Elas exploram esses temas políticos e sociais em diversas formas e formatos. No videoclipe da canção "Gira" (2019), por exemplo, Larissa Luz traz os ritos da religião de matriz africana em um contexto pop que dialoga com o afrofuturismo e o cyberpunk. A letra fala da luta racial atual em referência à opressão do passado: "A cada passo para frente a casa grande treme / Entro na sua mente, vê se não quebre a corrente / Pegue a coragem e junte com a sua fúria / Vejamos a mistura, vamos botar o bloco na rua". A canção é composta por Larissa Luz, em parceria com Bia Ferreira e Doralyce, jovens compositoras negras feministas. Ao analisar shows, álbuns e canções, percebemos que essa cena em que se insere o Aya Bass é o resultado de uma articulação de uma série de práticas que dão visibilidade a uma luta política em que se compartilha uma intensa e sensível experiência estética (Rancière, 2005). Neste sentido, as cantoras Larissa, Luedji e Xênia trazem uma ideia de pertencimento a uma cena que engloba elementos transnacionais

\footnotetext{
${ }^{19}$ Bloco afro mais antigo do carnaval de Salvador, fundado em 1974, no bairro do Curuzu.

${ }^{20}$ Bloco afro fundado em Salvador, em 1979, e criador do gênero samba-reggae.

Dossiê A Música e suas Determinações Materiais - https://revistaecopos.eco.ufri.br/ ISSN 2175-8689-v. 23, n. 1, 2020

DOI: 10.29146/eco-pos.v23i1.27454
} 
(afrofuturismo, bases eletrônicas, racismo, sexismo), mas interpelados por elementos especificamente locais como o candomblé, os ritmos afro-baianos, o grave dos blocos afro, a luta étnico-racial, a desigualdade social. Neste contexto, nos parece que a performance das Aya Bass encena um modo de estar no mundo, de compartilhar e ser afetado por experiências em fluxos e refluxos, mostrando que o sujeito subalterno (mulher, negra, periférica) articula a ocupação de novas posições e mostra o poder da música como agente que orienta movimentos sociais.

\section{É o novo som de Salvador?}

A circulação pelas cenas musicais de Salvador nos permite afirmar que essas características político-estéticas das artistas são compartilhadas com outros grupos e artistas como BaianaSystem, ÀTTOOXXÁ, Afrocidade, Baco Exu do Blues e Josyara, ainda que cada umx apresente as suas especificidades. 0 BaianaSystem se apropria de gêneros como pagode, arrocha, samba-reggae, com o uso de bases eletrônicas e sons graves. 0 ÀTTOOXXÁ, por sua vez, vai basear sua sonoridade em experimentações do groove do pagode baiano ${ }^{21}$ com beats digitais. Já Baco Exu do Blues, projeto do rapper Diogo Moncorvo, faz referências, nos seus dois discos - Esú (2017) e Bluesman²2 (2018) -, à religiosidade afrobaiana, misturada a samples, batuques, batidas eletrônicas, referências aos Novos Baianos e uma rima potente de uma política cotidiana. A banda Afrocidade, que circula entre Salvador e Camaçari, cidade da região metropolitana da capital baiana, mistura rap, ritmos jamaicanos, baianos e africanos e um discurso político. Josyara, assim como Larissa Luz, Luedji Luna e Xênia França, é uma cantora negra e feminista, e faz uma conexão das sonoridades afro-baianas a um discurso político feminista, LGBTQI+ e étnico-racial.

21 O pagode baiano tem origem no samba de roda e no samba junino, e incorpora percussão a instrumentos eletrônicos e batidas dançantes como o funk, por exemplo. Entre xs principais representantes estão É o Tchan!, Harmonia do Samba, Psirico e Leo Santana. Muitxs estudiosxs observam uma diferença social e racial entre o pagode e o axé: o primeiro tem como origem xs jovens negrxs pobres periféricxs, enquanto o segundo teria surgido nas classes médias brancas/mestiças.

${ }^{22} 0$ clipe "Bluesman" conquistou o Grand Prix (GP) na categoria Entertainment for Music (entretenimento para música), do Cannes Lions 2019.

Dossiê A Música e suas Determinações Materiais - https://revistaecopos.eco.ufri.br/

ISSN 2175-8689-v. 23, n. 1, 2020

DOI: 10.29146/eco-pos.v23i1.27454 
Adriana Amaral (2015), em um artigo sobre ativismo de fãs, reflete como práticas de consumo cultural pop são ferramentas importantes para o aprendizado do ativismo político. Os estudos de Amaral estão focados nos fãs, mas a autora traz importantes contribuições para a compreensão do ativismo no ambiente da cultura pop, e ajuda a refletir sobre o papel dos artistas como ativistas e a "relação entre a indústria do entretenimento, participação política, cultura pop e mobilização social”. (Amaral et al, 2015, p. 152). 0 papel de ativista dos novos artistas no ambiente da cultura pop (Amaral, 2015), como coloca Simone de Sá, nos leva a superar "a dicotomia entre os mundos do consumo e do entretenimento de um lado e a cidadania e a política do outro". (2016, p. 57). Observamos como esses atores sociais provocam uma forte associação, que dificilmente é quebrada, dos atos estéticos como atuação política. Luedji Luna apresentar-se no Teatro Castro Alves lotado, o grupo Aya Bass ganhar destaque no Festival Sangue Novo e no Carnaval, ou misturar pagodão (música por excelência da periferia de Salvador) com bases graves da música eletrônica, em um processo de hibridismo do passado, do popular e da indústria do entretenimento, são formas de provocar dissensos, criar rupturas políticas/estéticas e promover novas experiências.

As cenas musicais, na proposição de Will Straw (2006), nos permitem pensar uma análise que busque no objeto três camadas: espetáculo de pessoas, sociabilidade e criação cultural, em que determinadas (e diversas) práticas musicais estejam interligadas com o espaço geográfico e, assim, estabelecendo uma rede de relações (cidade, indústria cultural, mídia) que interage de diversas formas. De acordo com Straw, cena é uma forma de cartografar consumos culturais em territórios, locais ou globais, que nos ajuda a compreender que certas práticas significativas são organizadas territorialmente e reconhecidas como significantes de um determinado discurso. Para a cena acontecer, ela precisa criar um circuito, uma circulação de pessoas e objetos culturais que deem visibilidade nos espaços urbanos, preenchendo a cidade com a convivência (conflituosa ou não) de diferentes e similares grupos.

Dessa forma, podemos perceber o surgimento de um conjunto de artistas, do qual o projeto Aya Bass é oriundo, que estão criando uma rede, que inclui desde os fãs até os profissionais envolvidos nas produções (produtorxs, iluminadorxs, técnicxs de som,

Dossiê A Música e suas Determinações Materiais - https://revistaecopos.eco.ufri.br/ 
roadies, entre outrxs). Os elementos que delimitam essa cena são justamente aqueles que estamos explorando desde o início do artigo: o ativismo musical, a experiência política/estética e a articulação de elementos transculturais nas práticas musicais. É uma cena que circula principalmente pelo Centro Histórico de Salvador (onde fica o Pelourinho) e pelo bairro do Rio Vermelho - e que tem no Carnaval o seu apogeu, pois as disputas que ali são colocadas transformam a festa anual no principal palco para negociações e tensões e o compartilhamento dessas novas experiências.

\section{Breves considerações}

Essa "militância musical", como coloca Herschmann e Fernandes (2014), é parte construtiva dessa cena de música pop de Salvador. Herdeiros diretos do Tropicalismo, do Mangue Beat, da Axé Music e da música negra de Salvador (Ilê Aiyê, Lazzo Matumbi, Olodum, Margareth Menezes, entre outrxs), essxs artistas ocupam a cidade com sonoridades que replicam uma espécie de resistência/incorporação com novos idiomas estéticos (Regev, 2013) e encenam uma atitude de independência, de autonomia criativa em relação ao chamado mercado musical baiano. Ativam um discurso racial e de gênero e se conectam a redes de música urbana independente local/global, com novas formas de distribuição e circulação, o que fomenta diferentes conflitos políticos, sociais e ideológicos entre músicxs, fãs, produtorxs e críticxs. São novas práticas musicais que incorporam elementos estéticos, sonoros, ideológicos, midiáticos e mercadológicos que as aproximam de uma música pop repleta de localismos e globalismos, conectada por múltiplas redes, que reorganizam a música de Salvador e proporcionam uma diferente experiência de cidade.

Como coloca Straw: “(...) a música participa da política urbana na medida em que a sua ocupação dos lugares nas cidades molda (de maneira ora resistente, ora conivente) cartografias da divisão social, da desigualdade e da tolerância" (2018, p. 323). Percebemos que atores da música pop de Salvador produzem uma construção de sonoridades, performance, política, para encenar uma Bahia popular, tradicional e contemporânea, desigual e segregada, a partir de gêneros como pagode, samba-reggae,

Dossiê A Música e suas Determinações Materiais - https://revistaecopos.eco.ufri.br/

ISSN 2175-8689 - v. 23, n. 1, 2020

DOI: 10.29146/eco-pos.v23i1.27454 
ijexá, com ritmos transnacionais como rap, $d u b$, afrobeat, funk; um ativismo político impulsionado por um discurso antirracista, feminista e contra a desigualdade social.

Essas articulações têm definido o que chamamos aqui de uma cena de música pop ativista em Salvador que aciona determinadas experiências em seu público e fomenta alianças que possibilitam a incorporação de diversos elementos da cultura afro-baiana em conexões transnacionais, trazendo a perspectiva de Simone Pereira de Sá (2011) segundo a qual as cenas musicais funcionam como uma construção coletiva, fluida, e a cidade como o lugar-chave para o entendimento na construção dessas experiências. 0 projeto Aya Bass representa um recorte importante nessa pesquisa, porque produz elementos que nos possibilitam uma análise no sentido de materializar aspectos estéticos, políticos, sociais e econômicos da cena de música pop ativista de Salvador. Aya Bass traz à tona afetos que fazem parte de uma dinâmica local e que permitem entender como a prática musical é um instrumento politicamente potente que possibilita o fortalecimento de uma rede formada, em grande parte, por mulheres negras e jovens, que estruturam suas experiências em uma cidade negro-mestiça, racista, sexista, desigual, violenta, excludente, e articulam o compartilhamento de uma experiência política/estética que aqui chamamos de música pop ativista de Salvador, que passa a dar visibilidade a esses corpos historicamente invisíveis.

\section{Referências bibliográficas}

AMARAL, Adriana.; SOUZA, Rosana Vieira.; MONTEIRO, Camila. "De westeros no \#vemprarua à shippagem do beijo gay na TV brasileira". Ativismo de fãs: conceitos, resistências e práticas na cultura digital. Galáxia (São Paulo, Online), n. 29, p. 141-154, jun. 2015. Disponível em: <http://dx.doi.org/10.1590/1982-25542015120250>. Acesso:18 de nov. 2018.

BENESSAIEH, Afef. Multiculturalism, Interculturality, Transculturality. In Benessaieh, Afef. Transcultural Americas/Amériques Transculturelles. Otawa: Les Presses de l'Université d'Ottawa, 2010.

BHABHA, Homi. Introdução. O Local da Cultura. Belo Horizonte: Editora UFMG/Humanitas, 1998.

BUTLER, Judith. Corpos em aliança e a política das ruas: notas para uma teoria performativa de assembleia. Rio de Janeiro: Civilização Brasileira, 2018.

Dossiê A Música e suas Determinações Materiais - https://revistaecopos.eco.ufri.br/

ISSN 2175-8689-v. 23, n. 1, 2020

DOI: 10.29146/eco-pos.v23i1.27454 
COLLINS, Patricia Hill. Pensamento feminista negro: o poder da autodefinição. In: HOLLANDA, Heloísa Buarque de (org). Pensamento Feminista: conceitos fundamentais. Rio de Janeiro: Bazar do Tempo, 2019.

DE CERTEAU, Michel. A invenção do Cotidiano. Petrópolis: Editora Vozes, 2014.

FERNANDES, Cíntia Sanmartim.; HERSCHMANN, Micael (org). Cidades Musicais: Comunicação, territorialidade e política. Porto Alegre: Sulinas, 2018.

FERNANDES, Cíntia Sanmartim, HERSCHMANN, Micael. A música de rua do Rio de Janeiro. São Paulo: Intercom, 2014.

GONZALES, Lélia. Por um feminismo Afro-latino-Americano. São Paulo: Caderno de Formação Política do Círculo Palmarino/USP, 1988.

GUERREIRO, Goli. A Trama dos Tambores. São Paulo: Editora 34, 2001.

GUMES, Nadja Vladi. A potência da narrativa político-estética do BaianaSystem no Carnaval de Salvador. In: FERNANDES, C. S.; HERSCHMANN, M (org). Cidades Musicais: Comunicação, territorialidade e política. Porto Alegre: Sulinas, 2018.

HAESBAERT, Rogério. Da Desterritorializacão à Multiterritorialidade. Anais do X Encontro de Geógrafos da América Latina - 20 a 26 de março de 2005 - Universidade de São Paulo.

Disponível em http://observatoriogeograficoamericalatina.org.mx/egal10/Teoriaymetodo/Conceptuales/19.p df. Acessado em 11 de dezembro de 2019.

HERSCHMANN, Micael. Cenas, Circuitos e Territorialidades Sônico-Musicais. In: JANOTTI JR., Jeder; SÁ, Simone Pereira de (orgs). Cenas Musicais. Guararema, SP: Anadarco, 2013.

JANOTTI JR, Jeder. Afeto, autenticidade e sociabilidade: uma abordagem do rock como fenômeno cultural. In: GOMES, Itânia M. Mota \& JACOB DE SOUZA, Maria Carmen. Media \& Cultura. Salvador: Edufba, 2003.

JANOTTI JR., Jeder; PIRES, Victor. Entre os afetos e os mercados culturais: as cenas musicais como formas de mediatização dos consumos musicais. In: JANNOTTI JR., Jeder e outros (orgs.). Dez anos a mil: mídia e música popular massiva em tempos de internet. Porto Alegre: Simplíssimo, 2011.

KILOMBA, Grada. Plantation memories: episodes of everyday racism. Berlim: Unrast, 2008.

MOURA, Beatriz. 0 sonho afro-americano de Xênia França. Vice Brasil. Disponível em: $<$ https://www.vice.com/pt br/article/pakm7m/xenia-franca-entrevista>. Acesso em: 20 de janeiro de 2020.

RANCIÈRE, Jacques. A Partilha do Sensível: estética e política. São Paulo: Editora 34, 2005.

REGEV, Motti. Pop-rock Music: Aesthetic Cosmopolitanism in Late Modernity. Cambridge: Polity Press, 2013.

Dossiê A Música e suas Determinações Materiais - https://revistaecopos.eco.ufri.br/

ISSN 2175-8689-v. 23, n. 1, 2020

DOI: 10.29146/eco-pos.v23i1.27454 
RIBEIRO, Djamila. O que é Lugar de Fala? Belo Horizonte: Editora Letramento, 2017.

RISÉRIO. Antonio. Carnaval Ijexá. Salvador: Corrupio, 1981.

SÁ, Simone Pereira de. WILL STRAW: cenas musicais, sensibilidades, afetos e a cidade. In: GOMES, Itania, JANOTTI, Jeder. Comunicação e Estudos Culturais. Salvador: Edufba, 2011.

. Somos Todos Fãs e Haters? Cultura Pop, Afetos e Performance de Gosto nos Sites de Redes Sociais. Revista ECO PÓS, v. 19, n.3. Rio de Janeiro, 2016. Disponível em: <https://revistas.ufri.br/index.php/eco pos/article/view/5421>. Acesso: 14 nov. 2018.

SHUKER, Roy. Vocabulário de música pop. São Paulo: Hedra, 1999.

SOVIK, Liv. Aqui ninguém é branco. Rio de Janeiro: Aeroplano, 2009.

STRAW, Will. Urbanização da política musical: cidades e cultura da noite. In: FERNANDES, Cintia San Martim, e HERSCHMANN, Micael (Org.). Cidades Musicais. Porto Alegre: Editora Sulinas, 2018.

Cena Visíveis e Invisíveis. In Adriana Amaral et al. Mapeando cenas da música pop: cidades, mediações e arquivos - Volume I. Paraíba: Marca de Fantasia, 2017.

Systems of Articulation, Logics of Change: Scenes and Communication in Popular Music. Cultural Studies, v. 5, n. 3, p. 368-388, Oct, 1991. Disponível em academia.edu

Scenes and Sensibilities. E-Compós, v. 6, n. 11. Brasília, 2006. Disponível em <http://www.e-compos.org.br/e-compos/article/view/83>. Acesso em 15 de março de 2019.

WOODWARD, Katheryn. Identidade e diferença: uma introdução teórica e conceitual. In: SILVA, Tomaz Tadeu da. Identidade e diferença: a perspectiva dos estudos culturais. Petrópolis: Vozes, 2000.

Dossiê A Música e suas Determinações Materiais - https://revistaecopos.eco.ufri.br/

ISSN 2175-8689-v. 23, n. 1, 2020

DOI: 10.29146/eco-pos.v23i1.27454 